\title{
Adolescent Involvement in Volunteerism in Relation to Identity and Educational and Occupational Expectations
}

\author{
Katie Snider
}

Follow this and additional works at: https://researchrepository.wvu.edu/etd

\section{Recommended Citation}

Snider, Katie, "Adolescent Involvement in Volunteerism in Relation to Identity and Educational and Occupational Expectations" (2016). Graduate Theses, Dissertations, and Problem Reports. 6680. https://researchrepository.wvu.edu/etd/6680

This Thesis is protected by copyright and/or related rights. It has been brought to you by the The Research Repository @ WVU with permission from the rights-holder(s). You are free to use this Thesis in any way that is permitted by the copyright and related rights legislation that applies to your use. For other uses you must obtain permission from the rights-holder(s) directly, unless additional rights are indicated by a Creative Commons license in the record and/ or on the work itself. This Thesis has been accepted for inclusion in WVU Graduate Theses, Dissertations, and Problem Reports collection by an authorized administrator of The Research Repository @ WVU. For more information, please contact researchrepository@mail.wvu.edu. 


\title{
Adolescent Involvement in Volunteerism in Relation to Identity and Educational and Occupational Expectations
}

\author{
Katie Snider \\ Thesis submitted to \\ The College of Education and Human Services \\ at West Virginia University
}

In partial fulfillment of the requirements for the degree of

Master of Arts

In Educational Psychology with an emphasis in:

Child Development and Family Studies

Carol Markstrom, Ph.D., Chair

Jessica Troilo, Ph.D.

Nancy Wolfe-Dilgard, M.S.

Department of Learning Sciences and Human Development

Morgantown, West Virginia

2016

Keywords: volunteerism, identity, fidelity, educational expectations, occupational expectations

Copyright 2016 Katie Snider 


\title{
Abstract \\ Adolescent Involvement in Volunteerism in Relation to Identity and Educational and \\ Occupational Expectations
}

\author{
Katie Snider \\ This study evaluated volunteerism, identity, and educational and occupational \\ expectations in order to look more closely at their relationships. The purpose was to fill the gap \\ in the existing literature on how adolescent volunteerism relates to identity development and \\ educational and occupational expectations. The study looked specifically at the type of volunteer \\ activity in which adolescents were involved and the amount of time they spent volunteering each \\ week. Data were collected from $50010^{\text {th }}$ and $11^{\text {th }}$ grade students in non-urban West Virginia \\ schools. Measures included a volunteer questionnaire, the Extended Objective Measure of Ego \\ Identity Status (EOMEIS), the Psychosocial Inventory of Ego Strengths (PIES), and the Life \\ Goals Questionnaire. Results showed that adolescents who spent 6-20 hours per week \\ volunteering were more likely to score in identity achievement and higher in fidelity compared to \\ those adolescents who spent less time volunteering. Additionally, more time spent volunteering \\ was related to volunteering in interpersonal helping activities. Finally, adolescents who \\ volunteered in interpersonal helping volunteer activities were more likely to expect to have a job \\ helping others at the age of 25. \\ Keywords: volunteerism, identity, fidelity, educational expectations, occupational \\ expectations
}




\section{Acknowledgements}

I would like to thank my entire family for their unwavering support during the last $2 \frac{1 / 2}{2}$ years as I completed my Master’s degree. I would especially like to thank my husband for being supportive during the endless hours I spent working on my research and my parents for being so helpful with my son, Jordan. I could not have made it through without all of you.

I would like to thank my committee chair, Dr. Carol Markstrom, and my committee members, Dr. Jessica Troilo and Nancy Wolfe-Dilgard. I have learned a lot from all of you and appreciate all your patients and the wisdom you have shared with me. 


\section{Table of Contents}

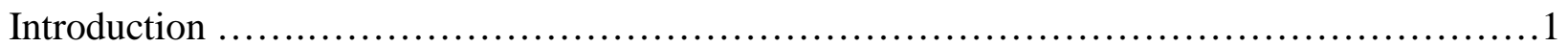

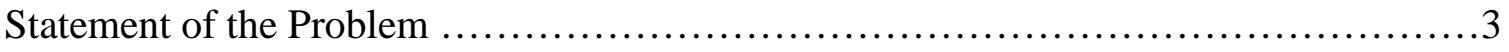

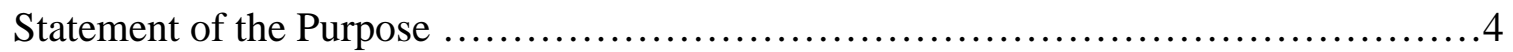

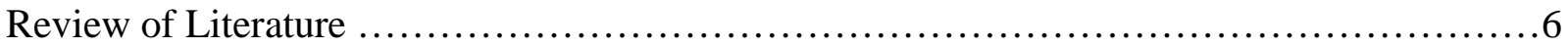

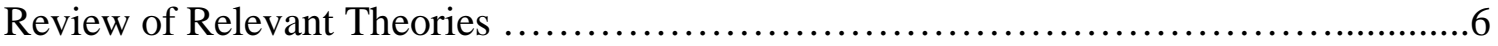

Positive Youth Development ..................................................6

Adult-Sponsored Structured Youth Activities ................................7

Volunteerism and Civic Engagement .................................

Erikson’s Psychosocial Theory ..............................................

Review of Relevant Research Studies ........................................12

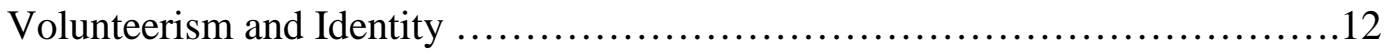

Volunteerism and educational and occupational expectations ...................17

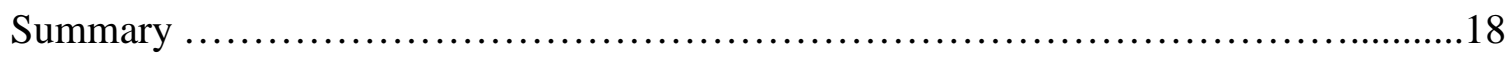

Hypotheses ................................................................... 19

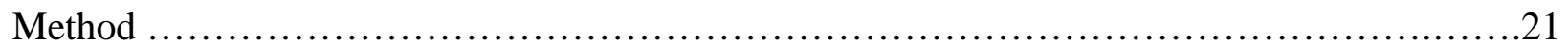

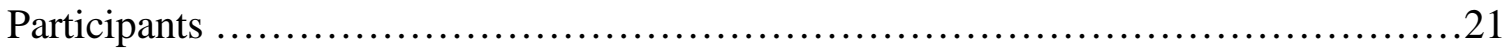

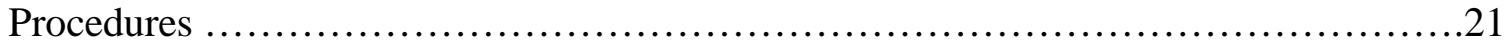

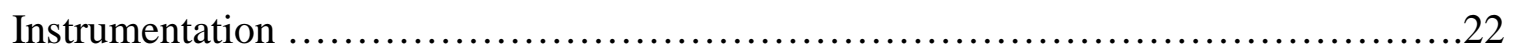

Volunteerism Questionnaire ..............................................22

Extended Objective Measure of Ego Identity Status ........................22

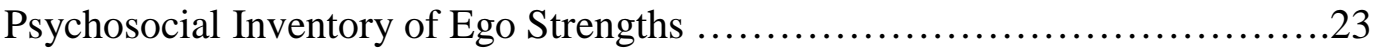

Life Goals Questionnaire ...............................................24 
Results

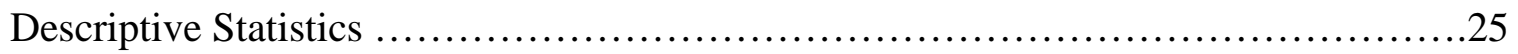

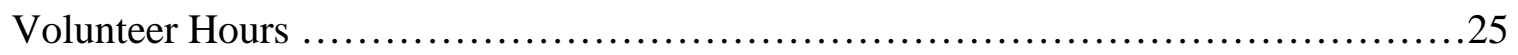

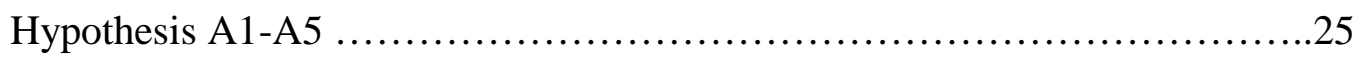

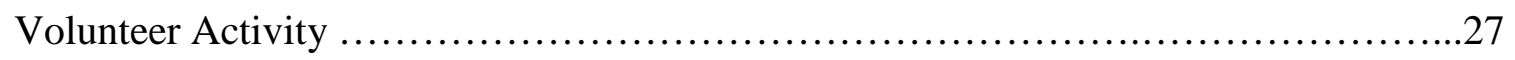

Hypothesis B1-B5 .............................................27

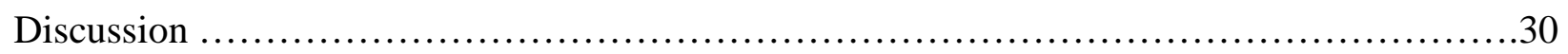

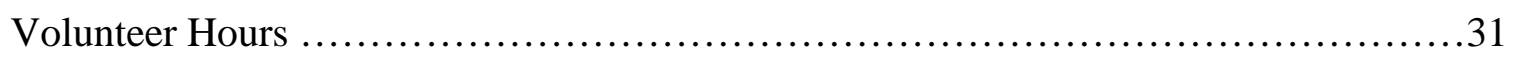

Hypothesis A1-A5 .................................................... 31

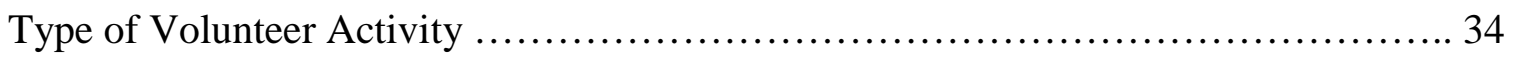

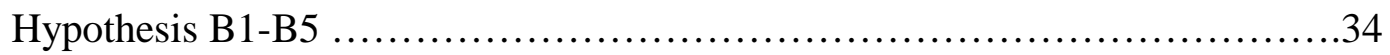

Limitations and Recommendations for Future Research ...........................36

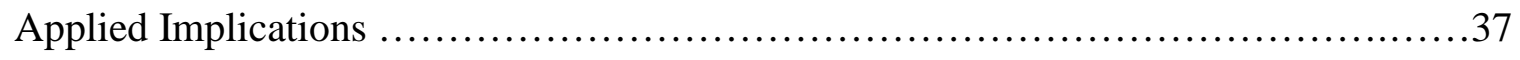

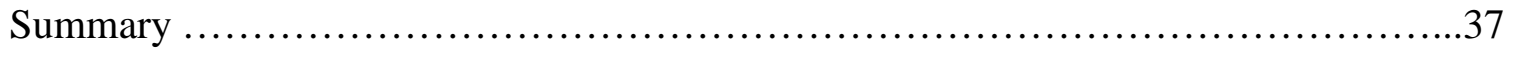

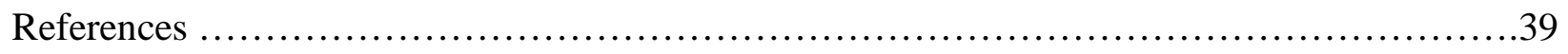




\section{List of Tables}

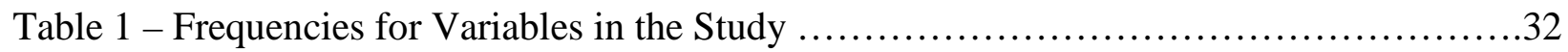

Table 2 - Frequency Counts and Percentages of Identity Status by Volunteer Hour

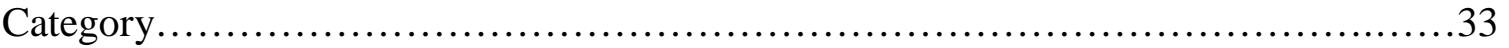

Table 3 -Results for ANOVA for Fidelity by Volunteer Hours ...............................34

Table 4 - Results for ANOVA for Volunteer Activity and Fidelity ..........................35

Table 5 - Frequency Counts and Percentages of Future Job Expectation by Volunteer Activity for the Total Sample of Those Who Volunteered ..............................36

Table 6 - Frequency Counts and Percentages of Future Job Expectation by Volunteer

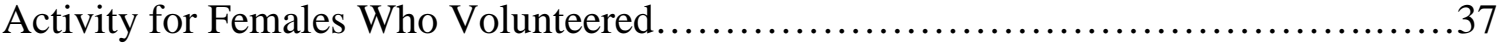




\section{List of Appendices}

Appendix A - Parental Consent Form ..................................................51

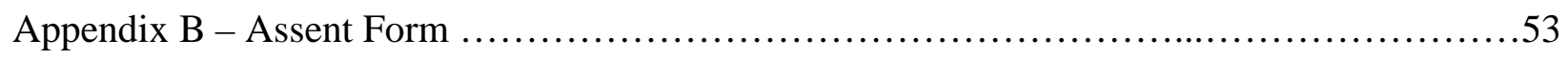

Appendix C - Volunteerism Questionnaire .........................................54

Appendix D - The Extended Objective Measure of Ego Identity Status .......................55

Appendix E - Fidelity Subscale of the Psychosocial Inventory of Ego Strengths ...............58

Appendix F - Life Goals Questionnaire ...............................................59 


\section{Introduction}

This project looked at the impact of adolescent volunteerism on identity formation along with that part of identity that taps into educational and occupational expectations. Adolescence is a transitional period between childhood and adulthood that involves rapid growth in physical, psychological, sociocultural, and cognitive development (Crosby, Santelli, \& DiClemente, 2009). Physical changes include those brought on by the onset of puberty. In the social realm, adolescents spend more time away from their parents, resulting in more independence and expansion of their social world. They also begin to experience advancements in cognitive abilities as their thinking and reasoning abilities become more complex. These developmental changes set the stage for identity exploration as adolescents try out various activities, start working in jobs, and begin thinking about their future. According to Erikson (1968), adolescents seek to find a balance between who they feel they are and how others see them in order to form their identity. Adolescents are also searching for their place in society, and begin setting goals for their future. Part of identity formation includes occupational identity and expectations for the future. The activities the adolescent engages in can impact their expectations for a future education and occupation. Volunteer programs can provide adolescents with experiences to help others, learn new skills, and discover new interests. Adolescents are not only figuring out who they are at the moment, but also who they want to be in the future. Determining their educational and occupational expectations for their future is a part of this process.

It was proposed in this study that volunteerism would be an important avenue for advancing identity formation processes in adolescence along with clarification of future educational and occupational expectations. Volunteerism involves any activity in which the individual participates by their own free will, without compensation, and that benefits another 
person, group, or cause. By giving of themselves to other individuals, causes and organizations, adolescents learn more about themselves, their interests, and their skills, which is all part of exploring identity options.

In addition to enhancements to identity formation, volunteering also gives adolescents something productive to do with their down time thereby deterring them from potential problem behaviors. Use of time is an important consideration in adolescent development. According to Lerner et al. (2009), more is better when it comes to out-of-school time spent in quality programs, as three or more hours spent in these programs per week was related to thriving in youth. Large amounts of time spent in unsupervised peer contexts may exacerbate risk-taking behaviors. Preventing high-risk behaviors in adolescence is essential for achieving optimum outcomes. Quality youth activities, like volunteerism, provide an alternative outlet for adolescents to prevent them from engaging in risk-taking behaviors by giving them something more productive to do with their time (Barnes, Hoffman, Welte, Farrell, \& Dintcheff, 2007).

Quality volunteer programs promote Positive Youth Development (PYD), which offers support for the adolescent's emerging identity (Mueller, Lewin-Bizan, \& Urban, 2011). PYD programs, including volunteer opportunities, motivate adolescents to engage in activities that support their growth and development. It allows them to find things they are good at or enjoy doing. Providing youth with positive learning and social experiences gives them something to feel good about and motivates them to want to do good things for themselves, their family, community, and society (Hershberg, DeSouza, Warren, Lerner \& Lerner, 2014). Engaging in these programs allows adolescents an opportunity to explore and try out various identities before committing by offering various contexts and experiences. 


\section{Statement of the Problem}

Available research on the positive impacts of volunteer participation on identity development is promising, but limited. There is also a lack of research available that looks at how the amount of time spent volunteering and the type of volunteer work can make a difference in the adolescents' identity formation and educational and occupational expectations. Volunteer activities can vary based on their purpose. In this thesis, volunteer activities were classified as interpersonal helping activities, which involve directly working with others, and task-based activities, which do not involve directly working with others. These two types could offer different experiences and possibly have different impacts on the individual. It is important to look at how adolescents' use of time relates to and potentially impacts their development including serving as a deterrent to engagement in risky behaviors.

There are many risk factors associated with youth problem behavior including lack of a positive connection to their community (Krystal, 1998), lack of a family bond (Wong, 2005), and too much unsupervised time spent with peers (Barnes et al., 2007). Hirschi’s (1969) social control theory of delinquency states that deviant behaviors occur due to the individual's lack of connection to society. This theory is based on the idea that involvement in conventional activities (e.g. volunteerism, civic engagement, employment) keeps an individual busy and engaged with society thereby preventing opportunities to engage in delinquent behavior. These conventional activities could be protective factors that prevent adolescent risk-taking behavior. Studies have shown that out of school activities which are prosocial, goal-oriented, and supervised by adults are associated with less antisocial behavior (Fleming et al., 2008). Research has shown that adolescents who are at-risk for problem behaviors are less likely to develop a solid sense of identity (Crocetti, Klimstra, Hale, Koot, \& Meeus, 2013). Lacking identity 
commitment and engaging in delinquent behaviors could cause a downhill spiral (Crocetti et al., 2013) resulting in poor academic achievement and lack of motivation to set academic or career goals. Immature identity formation and lack of goal setting are risk factors for adolescence that we need to understand better through research.

\section{Statement of the Purpose}

The positive youth development perspective stresses the importance of alignment among all resources available to the adolescent. Families, schools, and communities contribute to the development of our youth (Balsano, Phelps, Theokas, Lerner \& Lerner, 2009). It is important to understand the process of identity formation during adolescence and the impact that structured activities can have on their long-term development. Therefore, one purpose of this study was to determine the relations between adolescents’ involvement in volunteerism on identity development. A second purpose of this study was to determine if involvement in these programs was related to educational and occupational expectations. A third purpose of this study was to fill a gap in the literature on how the amount of time spent volunteering and the type of volunteer activity were related to adolescent identity development and educational and occupational expectations.

It is imperative that we find ways to engage youth in activities that promote a positive identity and also an investment in their community. Recent research shows the developmental benefits of adult-sponsored structured youth activities and programs that promote positive youth development (Balsano et al., 2009). Some of these benefits include better academic performance, less delinquent behavior, and exposure to caring adults (Bartko \& Eccles, 2003). However, research is limited on how these programs can help shape the adolescent's educational and occupational expectations. Research is even more limited on the impact of different types of 
volunteer work. Therefore, this thesis assisted in filling the gap in the current literature on the relationship between the amount of time spent volunteering and the type of volunteer activity on identity development and educational and occupational expectations.

\section{Summary}

During the adolescent years, youth begin spending more time with peers and less time at home with their family. Current research has shown that how adolescents spend their time matters (Mueller et al., 2011). When youth spend their leisure time engaged in activities that are goal-oriented and supervised by adults, they are less likely to engage in deviant behavior than when they are spending large amounts of unsupervised time in peer contexts. Volunteer activities are a good way for youth to spend their leisure time and bond with society under adult supervision and guidance. Volunteering allows youth the opportunity to explore various roles to aide in identity formation. It can also provide the youth with experiences that help to encourage educational and occupational expectations. Having a solid sense of identity and future expectations will assist the adolescent in achieving optimal developmental outcomes. It is important for researchers to study the impact of volunteerism on identity formation as well as the long-term benefits associated with setting educational and occupational expectations. 


\section{Review of Literature}

\section{Overview of Review of Literature}

This chapter is a review of previous relevant research about the role of youth participation in adult-structured and volunteer activities on their identity formation and educational and occupational expectations. Positive youth development, as well as Erikson's psychosocial theory, offer theoretical orientations to the topic and are discussed. Specifically, positive youth development activities are those guided by adults and aimed toward providing adolescents with experiences that encourage their personal strengths and interests. These experiences can assist with exploration, according to psychosocial theory. Exploration assists adolescents in finding what their interests are and what makes up their identity. A strong sense of identity helps adolescents make future decisions about what they want to be and what goals they want to achieve in life. In addition to reviewing research on youth development and identity development, the terms “adult-sponsored structured youth activities," "volunteerism,” and "civic engagement" are defined. Finally, research on youth participation in these programs is summarized followed by a list of hypotheses for this study.

\section{Review of Relevant Theories}

Positive Youth Development Perspective. The Positive Youth Development (PYD)

perspective focuses on adolescents’ potential strengths, qualities, and outcomes (Lerner, Phelps, Forman, \& Bowers, 2009) rather than focusing on the potential conflicts they may face as they transition to adulthood (Mariano \& Going, 2011). This theory is relevant to this study because volunteerism is an activity that promotes positive youth development. A key component of PYD is the promotion of desired outcomes and not simply preventing undesirable behaviors (Lerner et al., 2005). PYD programs promote competence, confidence, connection, character, and caring 
within adolescents, also referred to as the Five C's: competence, confidence, connection, character, and caring (Geldhof et al., 2014).

Competence refers to one's own view of their actions. Confidence refers to one's overall sense of self-worth. Connection includes the reciprocal bonds between people and resources. Character includes respect for societal rules, standards of appropriate behavior, integrity, and morals. Caring includes the ability to feel empathy and sympathy towards other people (Crocetti, Erentaite, \& Zukauskiene, 2014). Lerner et al. (2014) stated that when the Five C’s are manifested during the adolescent years, the person is on a track that positively contributes to not only their self, but also the well-being of their family, community and society. Adolescents are less likely to engage in risk-taking behaviors if they feel more confident in themselves and feel more connected to their family and community. The Five C’s of PYD can be promoted through adult-sponsored structured youth activities, including volunteerism and civic engagement.

Adult-sponsored structured youth activities. Examples of adult-sponsored structured activities include extracurricular activities, volunteerism, and religious involvement. Positive developmental outcomes may result from involvement in these activities because they provide social connections that help make school more enjoyable; therefore, they apply themselves more to their academics and are less likely to drop out of school (Markstrom, Li, Blackshire, \& Wilfong, 2005).

Volunteerism and civic engagement. Volunteerism is one type of quality activity that promotes PYD. Many definitions exist for volunteerism, but overall it includes activities performed by an individual, by their own freewill, which benefit another person, group, or cause (McAllum, 2014). Other terms sometimes used synonymously with volunteerism are service 
learning, civic engagement, and community service. Civic engagement is a broader term that includes participation in volunteerism, local organizations, and any work that is for the betterment of the community (Voight \& Torney-Purta, 2013). Like volunteerism, civic engagement also involves the individual participating by their own free will without compensation for their time. Adolescence may be a particularly important time for volunteerism because the period of late adolescence into early adulthood is thought to be a critical period for key psychological developments that last throughout adulthood. This is an important time for development of altruistic identity (Johnson, Beebe, Mortimer, \& Snyder, 1998), or an unselfish regard for the well-being of others.

Identity formation is an important developmental task of adolescence as they try to figure out who they are and what their place is in this world (Crocetti et al., 2014). Volunteering fulfills different needs for each person, but some feel it is a way to express their individuality. Volunteering can help to form the social role identity by providing more social contexts to explore. The individual can also begin to feel good about the service they may be providing or the act of being selfless, which can help to shape their moral identity (Gronlund, 2011). Engaging in volunteer activities can help youth to feel connected to their community, which provides them with a sense of how they fit into the larger society.

While available research is promising, little research is available on the impact of volunteerism on youth. The research that exists on volunteerism is mostly about adults and is limited to looking at the attributes of the individual and the potential benefits they may receive from the volunteer activity. Studies have suggested that adults who volunteer have a better sense of belonging to their community (Johnson et al., 1998). Perhaps this sense of feeling tied to their community could help to motivate youth to make long-term goals for their future. Volunteering 
for various community organizations will give youth a variety of experiences they may not have otherwise received. These experiences may bring out certain interests that could lead to educational and/or occupational expectations.

In summary, the PYD perspective recognizes the importance of youth in activities that contribute to optimal identity development. PYD activities encourage and motivate youth to participate and succeed. Adult-structured youth activities can promote PYD through providing a meaningful way for youth to spend out of school time. These activities keep youth engaged, so they are less likely to participate in risk-taking behaviors. They also provide them with skills, experiences, and friendships. Volunteering their time to benefit another person or cause helps the youth to develop an altruistic identity. According to Erikson (1968), the adolescent years are the most important time for engaging in community involvement, as it is a period of soulsearching. Erikson's (1963) theory helps to explain the psychosocial conflict of identity versus identity confusion experienced during adolescence and the importance of achieving a solid identity.

Erikson's Psychosocial Theory. Erik Erikson's psychosocial theory of human development emphasized the positive contributions to development made by the ego. His theory includes stages from infancy through later adulthood with each stage requiring resolution of a psychosocial conflict (Erikson, 1963). The psychosocial stages an individual ascends through include: basic trust versus mistrust (birth to 1 year), autonomy versus shame and doubt (1 to 3 years), initiative versus guilt (3 to 6 years), industry versus inferiority (6 to 11 years), identity versus identity confusion (adolescence), intimacy versus isolation (early adulthood), generativity versus stagnation (middle adulthood), and integrity versus despair (old age) (Erikson, 1963). Although the eight ego strengths, or internal strengths, are present throughout the lifespan, once 
the conflict is resolved for the specific stage, the ego strength for that stage fully emerges (Markstrom, Sabino, Turner, \& Berman, 1997). The eight ego strengths associated with each psychosocial stage resolution are: hope from basic trust vs. mistrust, will from autonomy vs. shame and doubt, purpose from industry vs. inferiority, fidelity from identity vs. identity confusion, love from intimacy vs. isolation, care from generativity vs. stagnation, and wisdom from integrity vs. despair (Markstrom \& Marshall, 2007).

According to Erikson’s (1956) theory, the psychosocial conflict of adolescence is identity versus role confusion. Individuals experience a period of soul-searching during this developmental stage where they experiment with various values, goals, and characteristics and determine how they fit with previous characteristics that defined their self, before settling on which ones will make up their mature identity. His theory discusses the idea that when adolescents engage in societal organizations, it strengthens their budding work identity by allowing them to experiment and learn through different duties (Erikson, 1968). The ego strength of fidelity emerges as proof of successful resolution of the psychosocial stage of identity versus identity confusion (Markstrom, et al., 1997). Fidelity involves an internal preoccupation to be true, genuine, and fair to oneself and others (Markstrom \& Marshall, 2007).

In order to assess ego-identity more accurately, James Marcia (1966) developed four identity statuses. These statuses are based on the person's degree of exploration and commitment to an identity. The first, identity diffusion, describes an individual who lacks commitment to an identity, yet has not explored options. Identity foreclosure describes an individual who has made a commitment without exploration, likely due to strong parental influences. Identity moratorium describes an individual that is actively exploring options, but struggling to make a commitment. Identity achievement, describes an individual who has 
explored options, has considered occupational choices, and has made a commitment. They may have had parental influence, but ultimately they made their own decision. Students who reached identity achievement had positive developmental outcomes, including less likely to give up on difficult tasks (Marcia, 1966). Involvement in positive youth development programs may allow students the opportunity for identity exploration and assist them in making a commitment. They may learn new skills or interests that could lead to future educational and occupational expectations.

Both Erikson (1956, 1963) and Marcia (1966) discussed the importance of career goals in their research. In a study by Marcia (1966), he states that Erikson (1956) viewed adolescence as "a time of growing occupational and ideological commitment" (p. 551). He states that adolescents are faced with adult tasks, such as getting a job and becoming a functioning citizen in society. Resolving these tasks is important in developing their occupational identity. Erikson (1968) states, "it is the inability to settle on an occupational identity which most disturbs young people” (p. 132). He explains that they often over identify with people they look up to and can end up losing their individuality (Erikson, 1968). It is important that youth engage in activities, like volunteerism, which aide in identity development along with learning skills. This time of identity exploration also requires that the adolescent find ways to establish a relationship with society, but still maintain their sense of self (Marcia, 1966). According to Marcia (1966) when individuals achieve this ego identity, they are freer from anxiety and less affected by sudden changes in their environment. They are also less confused regarding their self-definition (Marcia, 1966). Volunteer activities are a good way for adolescents to connect with their community and develop their identity, while learning new skills that could lead to future career goals. Occupational identity is one domain of identity. 
In Marcia’s (1966) study he discusses his four identity statuses in terms of occupational identity exploration and achievement. He describes an individual who is identity achieved as having explored occupational choices and committed to an occupation on their own terms. The identity diffusion individual has not committed to an occupation, either because they have not explored options or due to lack of concern. An individual in moratorium is actively exploring occupational choices, but has not yet made a commitment. The foreclosure individual has made a commitment to an occupation, but with out serious exploration of choices. This individual has committed to an occupation based on what others have chosen for them (Marcia, 1966).

Volunteer activities provide an opportunity for adolescents to explore occupational identities.

In summary, Erikson’s psychosocial theory explains the importance of identity achievement during adolescence. Exploring identities is an important part of adolescence and they need to be provided with these experiences in order to figure out who they are and who they want to be, so that identity commitments can be achieved. Volunteer activities can provide adolescents with a context to explore interests and learn new skills, which could possibly aide in identity achievement. Occupational identity is also very important, so the adolescent can set future expectations for an education and occupation. The next section will review the available research on the positive benefits of volunteerism on youth specifically related to identity development and educational and occupational expectations.

\section{Review of Relevant Research Studies}

Volunteerism and Identity. The following studies show the specific relation between volunteerism and identity development. Studies examining civic engagement and identity are also reviewed because civic engagement shares many of the same characteristics of volunteerism, which are working for the betterment of an organization or community without 
compensation. Larson and Hansen (2006) conducted a study on the developmental and potentially negative experiences that youth experience in extracurricular activities. The sample included 2,280 eleventh graders from 19 diverse high schools. A mobile computer lab was set up in each classroom to administer the survey. The survey began with the youth activity inventory to find out the types of organized activities youth were involved in and the amount of time involved in each. Next, the students completed the YES 2.0 inventory, which inventoried their experiences in the activities they participated in within the past three months. Three scales were used to represent personal development experiences, the Identity Work scale, the Initiative scale, and the Emotional Regulation scale. Three scales were also used to represent interpersonal development experiences, the Teamwork and Social Skills scale, the Positive Relationships scale, and the Adult Networks and Social Capital scale. Five scales were used to represent negative experiences, the Stress scale, Inappropriate Adult Behavior scale, Negative Influences scale, Social Exclusion scale, and Negative Group Dynamics scale. Results showed that students in service activities reported higher rates of all three interpersonal development scales of teamwork, positive relationships, and adult networks. The results indicate volunteerism assists with both interpersonal and personal development, but especially interpersonal development in terms of social networking advancing prosocial behavior. One mission of volunteerism is to connect youth to the community, which was found in the results of this study. Community service involvement was associated with adult networks (Larson \& Hansen, 2006). These social networks can provide a context for identity exploration in adolescence and provides adult role models.

As discussed previously, fidelity is the ego strength that emerges from successful resolution of Erikson's psychosocial stage of identity versus identity confusion in adolescence. 
Erikson states that fidelity can only emerge due to the interplay between the individual and the social forces of community (Erikson, 1968). Recent research has supported this theory. A study by Markstrom et al. (2005), provided evidence that adult-sponsored structured youth activities could provide the social environment that is essential for identity development. For their study, 517 high school students completed questionnaires about their involvement in adult-sponsored structured activities as well as the Psychosocial Inventory of Ego Strengths (PIES). Results showed that involvement in certain extracurricular activities (sports, student government, issues groups, and volunteerism) were related to many ego strengths. There was a significant relationship between volunteerism and hope, will, purpose, competence, fidelity, care and wisdom (Markstrom et al., 2005). This study suggests that engagement in volunteerism helps adolescence to achieve the ego strength of fidelity, which is the outcome of a positive resolution of the identity crisis. Markstrom et al. used the same sample as in the present study, but they measured volunteerism according to having participated or not participated while more detailed aspects of volunteerism are assessed in the present study.

A study by Markstrom and Webster (2016) used a pretest and posttest design to look at the impact of adolescent participation in adult-sponsored structured activities on identity and self-efficacy. Participants included middle and high school students involved in a summer Junior Volunteer Program that was part of a community organization in West Virginia. During the 11week program, the adolescents engaged in various skill building, community service, recreational, and social activities. The pretest and posttest measures included the Identity Style Inventory (ISI-6G), the fidelity subscale of the Psychosocial Inventory of Ego Strength (PIES), and the General Self-Efficacy Scale (GSE). Results showed a higher informational style of identity orientation and higher score of fidelity score posttest compared to pretest, suggesting 
that involvement in adult-sponsored structured activities could aid in identity exploration and commitment. Results also showed significant advancements in self-efficacy posttest compared to pretest (Markstrom \& Webster, 2016). Therefore, the Markstrom and Webster (2016) experimental study provided evidence for the impacts of volunteerism on identity which is consistent with the predictions in the present study.

Youniss, McLellan, Su, and Yates (1999), looked specifically at the role of community service on identity development. They hypothesized that engagement in these activities would enhance the ability of youth to integrate into normal adult society as well as promote identity development. They used data from the Monitoring the Future survey, which is a study that has been ongoing since 1976. Every spring high school seniors complete a questionnaire about drug use as well as background characteristics. This study used data from Form 2, which asks about engagement in community service. Data was collected from 1988 to 1993 yielding 16,800 responses. Results showed that students who participated in school government and other school related activities were more likely to participate in community service and less likely to engage in substance use. The authors stated that adolescence is a crucial time of identity formation, so it is important to be exposed to the norms and values that community service activities provide. Daily activities are important in shaping their emerging self-definition. Students who engaged in community service were more likely to have political involvement and report religion as an important part of their identity (Youniss et al., 1999), suggesting that their volunteer experiences aided in identity commitments.

Crocetti, Erentaite and Zukauskiene (2014) looked at identity style and how it related to positive youth development and civic engagement. Their study included 1,633 adolescents between the ages of 14 to 19 years old. The civic engagement activities the adolescents were 
involved in included: school self-government, volunteering, and youth political and non-political organizations. The results showed that different identity styles (i.e., information-oriented, normative, and diffuse-avoidant) significantly differed on all of the Five C's of positive youth development. Results also showed that different identity styles differed significantly in the amount of civic engagement. Adolescents with an information-oriented style had higher levels on the Five C's and also a higher amount of civic engagement. The information-oriented style means the individual is more self-reflective and actively explores identity commitments. They defined themselves in terms of their goals, values, and standards. These individuals have positive interpersonal relationships due to their ability to express empathy and prosocial behaviors (Crocetti et al., 2013). Many school districts are seeing the positive developmental benefits of youth volunteerism and are beginning to require community service as part of the curriculum.

According to McLellan and Youniss (2003), school policies that require community service hours claim that students are learning to be better citizens and feel responsible for the betterment of society. Their study included high school students from two upper-middle class private Catholic schools. School A required community service as part of their religion curriculum and assisted students with finding suitable placements. School B required community service, however, it was not integrated within the curriculum. Students filled out a questionnaire at the beginning of each school year and again at the end of each school year. The first cohort was followed from 1994 to1997 and the second cohort was followed from 1995 to 1998. The results showed that students from school B were more likely to choose functionary work to fulfill their community service requirement. Functionary work was considered activities that lacked direction and need (e.g. sweeping and filing). Students from school A were more likely to choose social service activities. Social service activities required direct interaction 
between the student and the individuals they were helping (e.g. serving at the soup kitchen). These experiences provide youth with various experiences through participatory action. The authors stated that the results support the idea that schools should treat involvement in social service activities with the same level of importance as academics and athletics (McLellan \& Youniss, 2003), as the activities could assist the adolescent in exploring who they want to be, what makes them feel good about themselves, learn new skills, and find new interests. All of these support identity exploration and could assist with commitment.

The previously discussed research studies show evidence of a clear link between volunteerism and identity formation. Adolescence is an important time of identity formation, so it is a particularly crucial time for youth to be exposed to community service. The research findings suggest that volunteering assists adolescents in overcoming the identity crisis and in developing the ego strength of fidelity (Markstrom et al., 2005), increasing their interpersonal networks, and providing opportunities for identity exploration (Larson \& Hansen, 2006).

Volunteerism and educational and occupational expectations. Limited research is available on the impact of volunteerism on educational and occupational expectations. A longitudinal study by Johnson et al. (1998) that began in 1988, focused on youth volunteerism using a panel design. The panel was made up of randomly selected $9^{\text {th }}$ grade students from the St. Paul Public School District. The participants completed questionnaires in their high school classrooms once per year for each of their four years of high school. Ninety-three percent of the participants were maintained throughout the study. First, participants were asked if they volunteer without pay. If so, then additional questions asked about how many hours per week and the type of volunteer work in which they were engaged. Other questions were asked to measure school-related, psychological, work-related, and social outcomes. Results showed that 
boys and girls were equally likely to volunteer. Approximately $40 \%$ of participants reported that they were currently volunteering during at least one of the four data collection times. The results showed that engaging in volunteer activities during the senior year of high school had significant relations to educational plans, academic self-esteem, positive self-esteem, intrinsic work values, and community involvement (Johnson et al., 1998). They examined the impact of the level of involvement and contact with recipients, but the results were not significant (Johnson et al., 1998). This study suggests a link between volunteering and setting future educational and occupational expectations, which needs to be examined further. Unfortunately, there were no additional studies to review explicitly on volunteerism and educational and occupational expectations.

\section{Summary}

This chapter summarized the relevant theories and research findings that support the connection between volunteerism and identity formation, as well as educational and occupational expectations. Overall, the psychosocial theory explains the importance of identity development during adolescence and the PYD theory explains that quality activities, like volunteerism, could assist in achieving a solid identity. Youth need to be provided opportunities for identity exploration in order to reach achievement. It is important that adolescents not have too much unsupervised out-of-school time as boredom can lead to risk-taking behaviors. Adult-sponsored structured activities that support PYD can provide a more beneficial way for youth to spend their time. Volunteerism is an activity that supports PYD and may provide the opportunity for exploration. Therefore, volunteerism could support adolescence identity development. Overall, the research findings show that the volunteer environment is conducive for identity development. However, the research is extremely limited on the impact of these programs on educational and 
occupational expectations. This study is unique because it also looks at how the type of volunteer activity might matter, which has rarely been studied. It is important that we understand the developmental benefits of engaging our adolescents in these activities, including their future expectations. The purpose of this study was to examine the impact of participation in volunteer activities on youths' educational and occupational expectations. The following hypotheses were proposed:

\section{Hypotheses}

A Amount of hours per week volunteering:

A1 Volunteering more hours per week will be associated with identity statuses of moratorium and achievement.

A2 Volunteering more hours per week will be associated with a higher score in fidelity compared to volunteering fewer hours per week

A3 Volunteering more hours per week will be associated with an expectation to have a job helping others at age 25 .

A4 Volunteering more hours per week will be associated with the expectation to go to college right away.

A5 Volunteering more hours per week and the expectation to go into military service right away is explored in the analyses.

B Type of volunteer work (interpersonal or task-based):

B1 Involvement in interpersonal helping volunteer activities will be associated with identity achievement or moratorium and involvement in task-based volunteer activities will not be related to identity achievement or moratorium. 
B2 Interpersonal helping volunteer activities will be associated with a higher score in fidelity compared to task-based volunteer activities.

B3 Interpersonal helping volunteer activities will be associated with an expectation to have a job helping others at age 25 and tasked-based activities will not be associated with an expectation to have a job helping others at age 25 .

B4 Interpersonal helping volunteer activities will be associated with the expectation to go to college right away and tasked-based activities will not be associated with the expectation to go to college right away.

B5 Type of volunteer work and the expectation to go into military service is explored in the analysis. 


\section{Methods}

\section{Overview}

The self-report survey data used in this study was collected as part of a larger study. The larger study’s purpose was to examine adolescent involvement in various types of activities on adolescent psychosocial development and adjustment. The survey was administered at two separate times, eight months apart (spring and fall semesters). Only data from the first time of data collection are used in the present study and then only a subset of variables from the larger dataset are utilized.

\section{Participants}

The study participants included $10^{\text {th }}$ and $11^{\text {th }}$ grade high school students from non-urban counties in West Virginia. The ages of participants ranged from 15 to 18 years old. The total sample included 500 students, 201 males and 299 females. The $10^{\text {th }}$ grade participants included 117 males and 195 females. The $11^{\text {th }}$ grade participants included 84 males and 104 females. The majority, 92\%, identified as White American. The remaining ethnicities identified included African American, Latino, American Indian/White, and Italian/American.

\section{Procedures}

The surveys were administered in 16 rural and suburban high schools and 11 4-H County Extension offices and were administered to groups of students inside the high schools or 4- $\mathrm{H}$ Extension offices. Students answered self-report measures of volunteerism, occupational identity, fidelity and occupational and educational goals. Parents of prospective students were mailed a letter explaining the purpose and procedures of the study. They were asked to sign and return the consent form (Appendix A) for their child to participate. The adolescents also signed 
their own assent form (Appendix B) on the day of the study. Both signed parental consent and adolescent assent forms were required for participation.

Research assistants were trained to administer the survey booklet. The background questionnaire included questions about gender, age, and ethnicity. Parents' occupational status and education level were also reported.

\section{Instrumentation}

Volunteerism. One question was used to determine the amount of time involved in volunteer activities (see Appendix C). The question asked if they volunteer without pay and if so, how many hours per week. The range of hours was from 0 (not volunteering) to 20 hours per week. These values were categorized according to 0 (no volunteering), 1 (1-5 hours/week), and 2 (6-20 hours/week).

Another question that was analyzed asked adolescents to describe their volunteer activity. A range of types of volunteer activities was reported, therefore, these were divided into meaningful categories according to interpersonal helping (e.g. hospital, elderly, homeless, and child care work) and task-based helping (mechanic, secretarial, cleaning, and yard work). This variable was only analyzed for those who are involved in volunteer activity.

Ideological identity. The Extended Objective Measure of Ego Identity Status (EOMEIS) was used to assess ideological identity (Bennion, Adams, \& Huhn, 1989). This is a measure designed to assess the individual's overall identity development based on Marcia's four identity statuses (diffusion, moratorium, foreclosure, and achievement) by asking 64 questions on a Likert scale. The EOMEIS includes four domains to measure ideological identity and four domains to measure interpersonal aspects of identity development. The four domains of ideological identity are politics, religion, occupation, and philosophy. The four interpersonal 
domains are friendship, dating, gender roles and recreational activities. The current study uses only the 32-items that assess ideological identity because the occupational identity domain is included in this aspect of identity. The 32-items are answered on a 6-point Likert-type scale ranging from (1) strongly agree to (6) strongly disagree yielding either a categorical score of identity status (e.g., diffusion, foreclosure, moratorium, or achievement). Alternatively, a categorical score can be obtained for ideological diffusion, foreclosure, moratorium or achievement (see Appendix D) and it is this classification used in the present study. A sample statement from the subscale is, "It took me a while to figure it out, but now I really know what I want for a career.” Previous studies using the EOMEIS provide evidence of validity and reliability (Markstrom \& Hunter, 1999). In the present study, Cronbach’s alphas for each identity status were: .63 for diffusion, .74 for foreclosure, .64 for moratorium, and .66 for achievement.

Fidelity. The Psychosocial Inventory of Ego Strengths (PIES) was developed by Markstrom et al, (1997) to assess the eight ego strengths (hope, will, purpose, competence, fidelity, love, care, and wisdom). The PIES includes 64 self-report questions using a 5-point Likert scale to obtain a total ego strength score. The PIES is also broken into eight subscales to score each ego strength separately. For this study, we are interested in the ego strength of fidelity, because fidelity is the ego strength that is derived from successful resolution of the identity vs. role confusion crisis during adolescence. The fidelity subscale includes eight statements, which each individual chose the degree to which each statement fits the self (see Appendix E). An example statement from the subscale is "I prefer to be free-floating without having to worry about commitments to other people or things.” Five answer choices are provided on a scale from (5) describes me very well to (1) does not describe me well. The PIES has been shown to be valid and reliable in previous studies when validated against various 
psychosocial measures (Markstrom et al., 1997). For the present sample, Cronbach’s alpha was .63 for fidelity.

Educational and occupational goals. The Life Goals Questionnaire was included to measure the degree to which the individual is setting future goals for a career and education (see Appendix F). The first question asked the job they would like when they are 25 years old. Responses were divided into one of four categories: (1) jobs that help others (e.g., doctor, teacher), (2) professional jobs (e.g., lawyer, secretary), (3) labor jobs (e.g., mechanic, welder), and (4) artistic jobs (e.g., musician, fashion designer). Question two asked them what they expect to do after high school. They were asked to rate six different choices (1) go to business or trade school, (2) go to college, (3) get a job, (4) get married, (5) go into the service, and (6) have children, but only the items on college and military service were analyzed in the present study. A Likert-type scale was used with three answer choices (1) right away, (2) later on, and (3) not at all. 


\section{Results}

\section{Descriptive Statistics}

The sample for this study included $50010^{\text {th }}$ and $11^{\text {th }}$ grade students from non-urban counties in West Virginia. Table 1 shows the frequencies for the volunteer variables in the study including whether or not they volunteer, the number of hours spent volunteering (none, 1-5, or 620), the type of volunteer activity (interpersonal helping or task-based for those who volunteered), and the expectation to join the college or military (right away, later on, or not at all). Subjects who had missing data were not included in analyses of those variables.

Table 1

Frequencies for Variables in the Study

\begin{tabular}{|c|c|c|c|}
\hline \multirow[t]{2}{*}{ Volunteer } & \multicolumn{2}{|l|}{$\underline{\text { Yes }}$} & \multirow{2}{*}{$\begin{array}{l}\text { No } \\
327(65 \%)\end{array}$} \\
\hline & $173(35 \%)$ & & \\
\hline \multirow[t]{2}{*}{ Volunteer Hours } & $\underline{\text { None }}$ & $\underline{1-5}$ & $\underline{6-20}$ \\
\hline & 297 (59\%) & $103(21 \%)$ & $45(9 \%)$ \\
\hline \multirow[t]{3}{*}{ Volunteer Activity } & \multicolumn{2}{|c|}{ Interpersonal Helping } & $\underline{\text { Task-Based }}$ \\
\hline & $62(12 \%)$ & & 95 (19\%) \\
\hline & Right Away & $\underline{\text { Later on }}$ & $\underline{\text { Not At All }}$ \\
\hline College & 358 (72\%) & $78(16 \%)$ & $29(6 \%)$ \\
\hline Military & $28(6 \%)$ & $39(8 \%)$ & 376 (75\%) \\
\hline
\end{tabular}

\section{Hypothesis A1-A5: Volunteer Hours}

To test hypotheses A1, volunteer hours (none, 1-5 hours, and 6-20 hours) and ideological identity statuses (diffusion, foreclosure, moratorium, and achievement) were analyzed to 
determine if a significant relationship existed between the two variables. A crosstabulation and chi-square test was conducted for these variables along with sex, of which no sex differences were shown $\left(\right.$ male $=\chi^{2}(6, \mathrm{~N}=174)=6.85, p=.34$; female $\left.=\chi^{2}(6, \mathrm{~N}=262)=9.03, p=.17\right)$. For the total table, the chi-square test showed a significant result $\left(\chi^{2}(6, \mathrm{~N}=436)=14.99, p=.02\right)$. In examination of the cells in the crosstabulation table (see Table 2), those who volunteered 6-20 hours per week were the group most likely to score in identity achievement (30\%), where the expected count was 6.6 and the actual count was 13 with a standardized residual of 2.5. Those who did not volunteer any hours per week were the group least likely to score identity achievement (12\%), with an expected count of 43.2 and the actual count was 35 with a standardized residual of -1.3 .

Table 2

Frequency Counts and Percentages of Identity Status by Volunteer Hour Category

\begin{tabular}{lccclc}
\hline $\begin{array}{l}\text { Volunteer } \\
\text { Hours }\end{array}$ & Diffusion & Foreclosure & Moratorium & Achievement & Totals \\
\hline No Hours & $134(46 \%)$ & $51(18 \%)$ & $70(24 \%)$ & $35(12 \%)$ & 290 \\
$1-5$ Hours & $36(35 \%)$ & $25(25 \%)$ & $24(25 \%)$ & $17(17 \%)$ & 102 \\
$6-20$ Hours & $14(32 \%)$ & $5(11 \%)$ & $12(27 \%)$ & $13(30 \%)$ & 44
\end{tabular}

Fidelity was examined in a 3 (volunteer hours) X 2 (sex) ANOVA (see Table 2) to test hypothesis A2. Results were significant $(F(2,439)=7.07, p=.001)$ for volunteer hours as more hours spent volunteering was significantly related to a higher score of fidelity. Table 2 shows the mean fidelity scores for each of the three volunteer hour categories. A greater amount of time spent volunteering was related to a higher score of fidelity. The results for the interaction between sex and volunteer hours were not significant $(F(2,439)=2.16, p=.117)$. 
Table 3

Results of ANOVA for Fidelity by Volunteer Hours

\begin{tabular}{lccccc}
\hline $\begin{array}{l}\text { Amount of } \\
\text { Volunteer } \\
\text { Hours }\end{array}$ & M & SE & df & F & p \\
\hline No Hours & $29.68^{\mathrm{b}}$ & .26 & 2 & 7.07 & .001 \\
$1-5$ & $30.58^{\mathrm{b}}$ & .45 & & & \\
$6-20$ & $32.31^{\mathrm{a}}$ & .69 & & & \\
\hline
\end{tabular}

Note: According to Tukey’s posthoc tests, means significantly different from one another are indicated by different superscript letters.

Hypotheses A3 was tested by analyzing volunteer hours and future job expectations to determine if a relationship existed between the number of hours spent volunteering each week and the expectation to have a job helping others at the age of 25. A crosstabulation and chisquare test was conducted for these variables and results were not significant (total $=\chi^{2}(4$, $\mathrm{N}=407)=8.37, p=. .08$ ). Analyses also checked for sex differences, which were not found (male= $\chi^{2}(4, \mathrm{~N}=160)=2.98, p=.56$; female $\left.=\chi^{2}(4, \mathrm{~N}=247)=5.57, p=.23\right)$.

Analyses were also conducted to see if a relationship existed between volunteer hours and the expectation to go to college (hypothesis A4) or join the military (hypothesis A5) right away. Results from the chi-square tests were not significant for the total sample (college $=\chi^{2}(4$, $\mathrm{N}=414)=5.8, p=.22$; military $\left.=\chi^{2}(4, \mathrm{~N}=399)=2.66, p=.62\right)$ and sex differences were not found for college $\left(\right.$ male $=\chi^{2}(4, \mathrm{~N}=165)=3.3, p=.51$; female $\left.=\chi^{2}(4, \mathrm{~N}=249)=4.17, p=.38\right)$ or military $($ male $=$ $\chi^{2}(4, \mathrm{~N}=156)=2.6, p=.63$; female $\left.=\chi^{2}(4, \mathrm{~N}=243)=3.48, p=.48\right)$.

\section{Hypothesis B1-B5: Volunteer Activity}

The type of volunteer activity (interpersonal helping and task-based) and identity status (diffusion, foreclosure, moratorium, and achievement) were analyzed to determine if a 
relationship exists between interpersonal helping volunteer activities and moratorium and achievement identity statuses to test hypothesis B1. The results of the chi-square tests were not significant (total $=\chi^{2}(3, \mathrm{~N}=163)=2.48, p=.48$; male $=\chi^{2}(3, \mathrm{~N}=59)=3.0, p=.39$; female $=\chi^{2}(3$, $\mathrm{N}=104)=3.94, p=.27)$.

To test hypothesis B2, fidelity was examined according to type of volunteer activity and sex in a 2 (type) X 2 (sex) ANOVA, which was significant. Those who volunteered in interpersonal helping activities scored significantly higher on fidelity compared to those in taskbased volunteer activities $(F(1,161)=5.66, p=.019)$. The type $X$ sex interaction was not significant $(F(1,161)=.913, p=.34)$. Table 3 shows the mean fidelity scores for both categories of volunteer activity (interpersonal helping and task-based).

Table 4

Results of ANOVA for volunteer activity and fidelity

\begin{tabular}{llllll}
\hline $\begin{array}{l}\text { Volunteer } \\
\text { Activity }\end{array}$ & $\mathrm{M}$ & $\mathrm{SE}$ & $\mathrm{df}$ & $\mathrm{F}$ & $\mathrm{p}$ \\
\hline $\begin{array}{l}\text { Interpersonal } \\
\text { helping }\end{array}$ & 32.60 & .67 & 1 & 5.66 & .02 \\
\begin{tabular}{l} 
Task-based \\
\hline
\end{tabular} & 30.69 & .44 & & & \\
\hline
\end{tabular}

Volunteer activity and future job expectation were analyzed to determine if a relationship exists to test hypothesis B3. The chi-square tests showed significance for the total sample $\left(\chi^{2}\right.$ (2, $\mathrm{N}=155)=12.39, p=.02)$. Those who volunteered in interpersonal helping activities were the group most likely to report an expectation to have a job helping others at age 25, where the expected count was 26.4 and the actual count was 37 with a standardized residual of 2.1. Those involved in task-based volunteer activities were the group least likely to report an expectation to 
have a job helping others at age 25, where the expected count was 39.6 and the actual count was 29 with a standardized residual of -1.7 . In examination of the cells in the crosstabulation table for the total sample (see Table 5), the group involved in interpersonal helping volunteer activities (60\%) had higher reports of an expectation to work in a job directly helping others at the age of 25 compared to those in task-based volunteer activities (31\%). Those in task-based volunteer activities (54\%) had higher reports of an expectation of a non-helping job at the age of 25. The results for females were also significant $\left(\chi^{2}(\mathrm{~N}=99)=13.62, p=.001\right)$. In examination of the cells in the crosstabulation table, females (69\%) involved in interpersonal helping volunteer activities were more likely to report an expectation to work in a job helping others (see Table 6), where the expected count was 26.7 and the actual count was 34 with a standardized residual of 1.4, compared to males (23\%) in interpersonal helping volunteer activities. The results for the table for males was not significant $\left(\chi^{2}(2, \mathrm{~N}=56)=4.28, p=.12\right)$.

Table 5

Frequency Counts and Percentages of Future Job Expectation by Volunteer Activity for the Total Sample of Those Who Volunteered

\begin{tabular}{lllll}
\hline & \multicolumn{3}{c}{ Job Category } \\
\cline { 2 - 5 } Volunteer & $\begin{array}{l}\text { Direct } \\
\text { Activity }\end{array}$ & $\begin{array}{l}\text { Non- } \\
\text { Helping }\end{array}$ & Undecided & Totals \\
\hline $\begin{array}{l}\text { Interpersonal } \\
\text { Helping }\end{array}$ & $37(60 \%)$ & $19(30 \%)$ & $6(10 \%)$ & 62 \\
Task Based & $29(31 \%)$ & $50(54 \%)$ & $14(15 \%)$ & 95 \\
\hline
\end{tabular}


Table 6

Frequency Counts and Percentages of Future Job Expectation by Volunteer Activity for Females Who Volunteered

\begin{tabular}{lllll}
\hline & \multicolumn{4}{c}{ Job Category } \\
\cline { 2 - 5 } $\begin{array}{l}\text { Volunteer } \\
\text { Activity }\end{array}$ & $\begin{array}{l}\text { Direct } \\
\text { Helping }\end{array}$ & $\begin{array}{l}\text { Non- } \\
\text { Helping }\end{array}$ & Undecided & Totals \\
\hline Interpersonal & $34(69 \%)$ & $9(18 \%)$ & $6(12 \%)$ & 49 \\
Helping & $20(40 \%)$ & $27(54 \%)$ & $3(6 \%)$ & 50 \\
Task Based & & & & \\
\hline
\end{tabular}

Crosstabulations and chi-squares were also conducted to see if a relationship existed between the type of volunteer activity and the expectation to go to college (hypothesis B4) or join the military (hypothesis B5) right away. Results from the chi-square tests were not significant for college (total $=\chi^{2}(2, \mathrm{~N}=156)=2.67, p=.26$; male $=\chi^{2}(2, \mathrm{~N}=56)=1.73, \mathrm{p}=.42$; female $\left.=\chi^{2}(2, \mathrm{~N}=100)=1.86, p=.39\right)$ or military $\left(\right.$ total $=\chi^{2}(2, \mathrm{~N}=146)=1.43, p=.49 ;$ male $=\chi^{2}(2$, $\mathrm{N}=51)=.18, p=.91 ;$ female $\left.=\chi^{2}(2, \mathrm{~N}=95)=1.66, p=.44\right)$.

\section{Discussion}

The purpose of this study was to determine the relationships between aspects of volunteerism and adolescent identity development and educational and occupational expectations. Relative to volunteerism, the amount of time and the type of volunteer activity were examined as independent variables. It was predicted that volunteering more hours per week would be related to ideological identity statuses of moratorium and achievement, higher fidelity, a greater expectation of a job helping others at age 25, and a greater expectation to go to college right away. It was also hypothesized that individuals in interpersonal helping volunteer 
activities would be more likely to score in identity moratorium or achievement status, score higher in fidelity, a greater expectation to have a job helping others at age 25, and a greater likelihood to expect to go to college right away.

\section{Volunteer Hours}

The relation between more volunteer hours and the identity status of achievement was significant, as predicted. The most meaningful relationships showed that those who did not volunteer were less likely to score in identity achievement and those who volunteered 6-20 hours per week were more likely to score in identity achievement. According to Marcia’s (1966) identity statuses, a period of exploration is necessary to achieve an identity. It could be that volunteer activities provide a context for identity exploration and that the volunteer experience provides opportunities to learn new skills. Perhaps it could also expose the individual to a variety of activities that may spark their interest. Therefore, spending more time involved in volunteer activities could potentially provide more opportunities to explore various identities thereby facilitating an identity commitment. The findings are consistent with Larson and Hansen's (2006) study, which showed volunteerism assists with both personal and interpersonal development by assisting in identity development through involvement in their community. The results are also parallel with the findings from Markstrom and Webster's (2016) study using pretest and posttest data that showed involvement in an adult-sponsored structured program that included community service resulted in identity exploration and commitment. The findings are also consistent with what Lerner et al. (2009) wrote about the importance of out-of- school time. They stated that the more out-of-school time spent in PYD programs, the better the outcomes (Lerner et al., 2009). Volunteerism is a PYD activity, which provides a more productive way for adolescents to spend their out-of-school time, so they are less likely to engage in risky behaviors 
(Barnes et al., 2007). This is consistent with Hirschi’s (1969) social control theory that keeping youth engaged in society will keep them too busy to engage in risk-taking behaviors. No sex differences were found in the current study suggesting that volunteering is advantageous for both males and females.

It is surprising that identity moratorium was not significant as predicted. Perhaps this can be explained because achievement is more advanced, involving a commitment, whereas moratorium is less mature and the person is still exploring identities. This could mean that volunteerism helps with advanced exploration toward commitment (i.e., identity achievement), which is consistent with the next finding showing that the more time spent volunteering was related to the ego strength of fidelity thereby supporting the hypothesis. Sex differences were not significant. Fidelity is the ego strength that is derived from the successful resolution of the identity crisis in adolescence. Volunteer activities provide contexts to explore various identities, therefore, more time spent in these activities can aide in identity achievement and ultimately the ego strength of fidelity. These findings were consistent with those of Markstrom et al. (2005) who found a significant relationship between volunteerism and the ego strength of fidelity as well as other ego strengths.

It was hypothesized that more time spent volunteering would be associated with a greater expectation to work in a job helping others at the age of 25. However, the results did not support this hypothesis. The number of hours per week spent volunteering was not significantly related to the expectation to work in jobs helping others at the age of 25. There are many types of volunteer activities that individuals can participate in, some of which do not involve direct help to others. Volunteering can be directly helping others (e.g., reading to hospitalized children) or indirectly helping others (e.g., shoveling a walking trail). The amount of time spent in helping 
volunteer activities did not differentiate between future expectations. The type of volunteer activity itself may be a more meaningful influence than just simply volunteering, as discussed in a subsequent section. For example, volunteering time to file papers at a medical office is a taskbased activity that may not influence the individual to want to help other people in the future.

It was hypothesized that more time spent volunteering would be related to a greater likelihood to expect to go to college right away. However, the results did not support this hypothesis. The number of hours spent volunteering was not significantly related to the expectation to go to college. Therefore, volunteer experiences were not a factor in the expectation to go to college. The results showed that $72 \%$ of participants expected to go to college right away. This percentage may fit the normative expectation today with potentially the majority of adolescents expecting to go to college immediately after high school. So, volunteering or not volunteering may not be influential in that decision since most adolescents expect to go to college. There are also many reasons people choose to go to college apart from volunteering or not volunteering. For example, it may be due to the expectations set for them by their parents or they may simply think it is just the next step in life, or a variety of other reasons.

The relationship between volunteer hours and the expectation to join the military right away was also examined in an exploratory manner. The number of hours spent volunteering was not significantly related to the expectation to go to the military. Therefore, volunteer experiences were not a factor in the expectation to go to the military. Perhaps there are many motivations to join the military, which may include parents expectations or following in the footsteps of a parent. Adolescents may also think it is their only option after high school or they may plan to join in order to pay for college or a variety of other reasons. 
In summary, greater number of hours spent volunteering was associated with identity development according to identity achievement and the ego strength of fidelity. Both of these aspects of identity are similar because they reflect an advanced state of identity according to informed and explored commitments. Amount of time spent volunteering did not relate to the expectation to work in a job helping others as an adult. Also, perhaps due to numerous motivating factors, amount of time spent volunteering does not seem to be a factor in the expectation to go to college or join the military right away.

\section{Type of Volunteer Activity}

This thesis strived to fill the gap in the literature on whether the type of volunteer activity matters. It was hypothesized that individuals in interpersonal helping volunteer activities would be more likely to score in identity statuses of moratorium or achievement compared to those in task-based volunteer activities. The results did not support this hypothesis. This could be explained because all types of volunteer activities provide a context for identity exploration. Task-based volunteer activities are still providing a supervised context for adolescence to learn new skills and find new interests that they may not have otherwise known they had. These new interests and skills can help the adolescent to decide who they are and who they want to be in the future. Figuring out that they are interested in a certain type of task (e.g., filing) could lead to an occupational identity and setting a future occupational expectation (e.g., secretary).

It was also hypothesized that individuals in interpersonal helping activities would score higher in fidelity compared to those in task-based volunteer activities. The results supported this hypothesis. Volunteering in interpersonal helping activities was significantly related to a higher score of fidelity. Fidelity involves the preoccupation to be true, genuine, and fair to oneself and others (Markstrom \& Marshall, 2007). Volunteer activities that involve helping other people 
may foster the development of fidelity. They provide a context where the individuals can feel good about themselves for helping another person in need of some type of assistance. This desire to help others may become part of their identity due to these volunteer experiences allowing them to explore what makes them feel good about who they are now and who they want to be in the future.

The relationship between type of volunteer activity and the expectation to work in jobs helping others at age 25 was also examined. The results of the total sample supported the hypothesis that involvement in interpersonal helping volunteer activities would be related to the expectation to have a future job helping others. In addition, females in interpersonal helping volunteer activities were significantly more likely to expect to have a job helping others in the future. This is likely due to females traditionally playing more of a caretaker role than males. Society expects women to care for children and the elderly more than males, therefore this could impact the types of volunteer activities females choose to engage in and ultimately the types of careers they choose. Adolescence is a time of clearly defining gender-role identities (Karniol, Grosz, \& Schorr, 2003). The gender socialization they have received throughout childhood is considered and they choose their own degree of masculine and feminine traits. Gilligan and Wiggins (1988) stated that females are socialized towards the ethic of care and empathy for others. These gender socializations could explain females increased motivation to directly help others.

The next hypothesis predicated a relationship between interpersonal helping volunteer activities and the expectation to go to college right away. Results did not support this hypothesis. Once again, this is likely due to the variety of reasons that people choose to go to college. Analyses were also conducted on the expectation to join the military right away and 
these results were also not significant. Volunteerism is not a significant factor that contributes to these expectations.

In summary, volunteerism is advantageous for identity exploration. The type of volunteer activity can play an important role in developing the ego strength of fidelity, as the study showed those involved in interpersonal helping activities had a higher fidelity score. These interpersonal helping activities can assist our youth in feeling good about helping someone else in need. Interpersonal helping volunteer activities can also result in an expectation of a future job helping others. Volunteer type, however, does not seem to be a motivating factor in the expectation to go to college or join the military right away.

\section{Limitations and Recommendations for Future Research}

In future research it will be important to look more closely at the type of volunteer activity and why it matters. Research is very limited on how task-based and interpersonal helping volunteer activities can have a different impact on identity development and educational and occupational expectations. It would also be helpful to include questions about adolescents’ motivations to volunteer. This could include being required by their school, their parents, courtordered community service, or their own desire to help others. A limitation of the current study was that the context of which the adolescents volunteered (e.g. faith based, 4-H, communitybased, own initiative) was unknown. Future research should look at the organization or entity of which the adolescent is involved which involves volunteerism.

A more diverse sample should also be used for future research. The sample for this study was predominantly White. All participants were in the state of West Virginia, which is located in Appalachia. Using a more diverse sample would make the results more generalizable. 
A pretest and posttest control group experimental design would be interesting for future research on this topic. This would allow comparisons to be made between data collected before they volunteered and after they spent time volunteering and in comparison to adolescents who do not volunteer. The data could show how volunteering impacted their long-term goals. It would also be interesting to compare their identity status before and after spending time in volunteer activities.

\section{Applied Implications}

The results of this study support the idea that volunteerism in adolescence is important for optimal development by showing that volunteerism aides identity development. Likewise, other researchers have shown the advantageous aspects of adolescent volunteerism (Barnes et al., 2007; Markstrom et al., 2005; Markstrom \& Webster, 2016). It also supports the idea that adolescents that engage in interpersonal helping volunteer activities are more likely to set future expectations of a job helping others. Adolescence is a sensitive time for identity development; therefore, it is important for everyone involved in the growth and development of our youth to encourage them to engage in societal organizations, like volunteerism, to support their developing occupational identity (Erikson, 1968).

\section{Summary}

The findings from this study show that it is advantageous for adolescents to participate in volunteer activities. Volunteering 6 or more hours per week was related to identity achievement. More time spent volunteering was also related to a higher score on fidelity. Therefore, engaging in regular volunteer activities positively impacts the adolescents' overall identity development. It assists them in figuring out who they are now, who they want to be in the future, and their desire to be true and fair to themselves and others. 
A strength of this study was the new way of measuring volunteerism based on two types. Interpersonal helping volunteer activities involved directly helping a person or cause (e.g., elderly, homeless shelter). The task-based volunteer activities did not involve directly helping a person or cause, but instead were focused on completing a task (e.g., mechanic, secretarial work). Results showed that the type of volunteer work did matter for the development of the ego strength of fidelity, as volunteering in interpersonal helping activities was related to higher scores of fidelity. The type of volunteer activity also mattered for future job expectation. Those in interpersonal helping activities were more likely to expect a job helping others at the age of 25.

Previous literature, as discussed in the review of literature, suggested a connection between volunteerism and identity development. This study adds to the research showing support for the positive impacts of volunteerism on identity development and taking it a step further to support the idea that the type of volunteer activity can matter. The study also found that type of volunteer activity in which they are involved could influence their future educational and occupational expectations, specifically for those in interpersonal helping activities. These topics should be explored further to reach a better understanding of the overall positive impact of volunteerism on the development of our adolescents. 


\section{References}

Balsano, A.B., Phelps, E., Theokas, C., Lerner, J.V., \& Lerner, R.M. (2009). Patterns of early adolescents’ participation in youth development programs having Positive Youth Development goals. Journal of Research on Adolescence, 19 (2), 249-259.

Barnes, G.M., Hoffman, J.H., Welte, J.W., Farrell, M.P., \& Dintcheff, B.A. (2007). Adolescents' time use: Effects on substance use, delinquency and sexual activity. Journal of Youth and Adolescemce, 36, 697-710.

Bartko, W.T. \& Eccles, J.S. (2003). Adolescent participation in structured and unstructured activities: A person-oriented analysis. Journal of Youth and Adolescence, 32 (4), 233241.

Bennion, L., Adams, G.R. (1986). Objective Measure of Ego Identity Status: A reference manual. There needs to be more info. If nothing else, published by author and name the university. This citation should be in one of my articles.

Crocetti, E., Erentaite, R., \& Zukauskiene, R. (2014). Identity styles, positive youth development, and civic engagement in adolescence. Journal of Youth and Adolescence, 43, 1818-1828.

Crocetti, E., Klimstra, T.A., Hale, W.W., Koot, H.M., \& Meeus, W. (2013). Impact of early adolescent externalizing problem behaviors in identity development in middle to late adolescence: A prospective 7-year longitudinal study. Journal of Youth and Adolescence, 42, $1745-1758$.

Crosby, R.A., Santelli, J.S., \& DiClemente, R. J. (2009). Adolescents at risk: A generation in jeopardy. In R.J. DiClemente (Ed.), J.S. Santelli (Ed.), \& R.A. Crosby (Ed.), Adolescent Health, (pp. 3-5). San Francisco, CA: Jossey-Bass. 
Erikson, E.H. (1956). The problem of ego identity. Journal of the American Psychoanalytic Association, 4, 56-121.

Erikson, E.H. (1963). Childhood and Society. ( $2^{\text {nd }}$ ed.). New York, NY: W.W. Norton.

Erikson, E. H. (1968). Identity: Youth and Crisis. New York, NY: W. W. Norton.

Fleming, C.B., Catalano, R.F., Mazza, J.J., Brown, E.C., Haggerty, K.P., \& Harachi, T.W. (2008). Journal of Early Adolescence, 28 (2), 277-303.

Geldhof, G.J., Bowers, E.P., Mueller, M.K., Napolitano, C.M., Callina, K.S., \& Lerner, R.M. (2014). Longitudinal analysis of a very short measure of positive youth development. Journal of Youth and Adolescence, 49, 933-949.

Gilligan, C., \& Wiggins, G. (1988). The origins of morality in early childhood relationships. In C. Gilligan, J. V. Ward, \& J. M. Taylor (Eds.), Mapping the moral domain (pp. 111138). Cambridge, MA: Harvard University Press.

Gronlund, H. (2011). Identity and volunteering intertwined: Reflections on the values of young adults. International Journal of Voluntary and Nonprofit Organizations, 22 (4), 852-874.

Hershberg, R.M., DeSouza, L.M., Warren, A. E., Lerner, J.V., \& Lerner, R.M. (2014).

Illuminating trajectories of adolescent thriving and contribution through the words of youh: Qualitative findings from the 4-H study of Positive Youth Development. Journal of Youth and Adolescence, 43, 950-970.

Hirschi, T. (1969). Causes of delinquency. Berkeley, CA: University of California Press.

Johnson, M.K., Beebe, T., Mortimer, J.T., \& Snyder, M. (1998). Volunteerism in adolescence: A process perspective. Journal of Research on Adolescence, 8 (3), 309-332. 
Karniol, R., Grosz, E, \& Schorr, I. (2003). Caring, gender role orientation, and volunteering. Sex Roles, 49(1/2).

Krytal, S. (1998). The nurturing potential of service learning. Educational Leadership, 56 (4), 58-61.

Larson, R.W. \& Hansen, D.M. (2006). Differing profiles of developmental experiences across types of organized youth activities. Developmental Psychology, 42 (5). 849-863.

Lerner, R.W, Abo-zena, M.M, Bebiroglu, N., Brittian, A., Lynch, A.D., \& Issac, S.S. (2009). Positive youth development: Contemporary theoretical perspectives. In R.J. DiClemente (Ed.), J.S. Santelli (Ed.), \& R.A. Crosby (Ed.), Adolescent Health, (pp. 115-128). San Francisco, CA: Jossey-Bass.

Lerner, J. V., Phelps, E., Forman, Y., \& Bowers, E. P. (2009). Positive youth development. In R. M. Lerner, L. Steinberg, R. M. Lerner, L. Steinberg (Eds.), Handbook of adolescent psychology, Vol 1: Individual bases of adolescent development (3rd ed.) (pp. 524-558). Hoboken, NJ, US: John Wiley \& Sons Inc.

Lerner, R.M., Lerner, J.V., Almerigi, J.B., Thokas, C., Phelps, E., Getsdottir, S., Naudeau, S., Jelicis, H., Alberts, A., Ma, L., Smith, L.M., Bobek, D.L., Richman-Raphael, D., Christiansen, E.D., \& Von Eye, A. (2005). Positive youth development, participation in community development programs, and community contributions of fifth-grade adolescents: Findings from the first wave of the 4-H study of positive youth development. Journal of Early Adolescence, 25 (1), 17-71.

Lerner, R.M, Wang, J., Chase, P.A., Gutierrez, A.S., Harris, E.M., Rubin R.O., \& Yalin, C. (2014), Using relational developmental systems theory to link program goals, activities, 
and outcomes: The sample case of the 4-H Study of Positive Youth Development. New Directions for Youth Development, 2014 (144), 17-30.

Marcia, J. (1966). Development and validation of ego-identity status. Journal of Personality and Social Psychology, 3 (5), 551-558.

Mariano, J. M., \& Going, J. (2011). Youth purpose and positive youth development. Advances In Child Development And Behavior, (41), 39-68.

Markstrom, C.A. \& Hunter, C.L. (1999). The roles of ethnic and ideological identity in predicting fidelity in African American and European American adolescents. Child Study Journal, 29 (1), 23-38.

Markstrom, C.A., Li, X., Blackshire, S.L., \& Wilfong, J.J. (2005). Ego strength development of adolescents involved in adult-sponsored structured activities. Journal of Youth and Adolescence, 34 (2). 85-95.

Markstrom, C.A \& Marshall, S.K. (2007). The psychosocial inventory of ego strengths: Examination of theory and psychometric properties. Journal of Adolescence, 30, 63-79.

Markstrom, C.A., Sabino, V.M., Turner, B.J., Berman, R.C. (1997). The psychosocial inventory of ego strengths: Development and validation of a new Eriksonian measure. Journal of Youth and Adolescence, 26 (6), 705-732.

Markstrom, C.A., \& Webster, A. (2016, March). Identity and self-efficacy development of adolescents in an adult-sponsored volunteer program. Poster presentation at the Annual Meetings of the International Society for Research on Identity Formation, Baltimore, MD.

McAllum, Kirstie. (2014). Meanings of organizational volunteering: Diverse volunteer pathways. Management Communication Quarterly, 28 (1), 84-110. 
McLellan, J.A. \& Youniss, J. (2003). Two systems of youth service: Determinants of voluntary and required youth community service. Journal of Youth and Adolescence, 32 (1), 47-58.

Mueller, M.K., Lewin-Bizan, S., \& Urban, J.B. (2011). Youth activity involvement and Positive Youth Development. Advances in child development and behavior, 49, 231-249.

Voight, A., \& Torney-Purta, J. (2013). A typology of youth civic engagement in urban middle schools. Applied Developmental Science, 17 (4). 198-212.

Wong, S.K. (2005). The effects of adolescent activities on delinquency: A differential involvement approach. Journal of Youth and Adolescence, 34(4), 321-333.

Youniss, J., McLellan, J.A., Su, Y., \& Yates, M. (1999). The role of community service in identity development: Normative, unconventional, and deviant orientations. Journal of Adolescent Research, 14 (2), 248-261. 


\section{Appendix A}

West Virginia University
$\begin{aligned} & \text { Wef Family and Consumer Sciences } \\ & \text { College of Agriculture, Forestry and Consumer Sciences }\end{aligned}$

PARENTAL, OR GUARDIAN CONSENT FORM - NON-CHARTING PARTICIPANTS

Effects of the 4-H Charting Program on the Development of Youth

Introduction. I have been asked to allow my adolescent to participate in this study. has explained the study to me. This study is being conducted by Dr. Carol Markstrom in the Division of Family and Consumer Sciences.

Purposes of the Study. I have been told that the purpose of this study is to learn more about a 4-H program called Charting. Charting is a six-month program for teenagers in 4-H who want to learn more about themselves and develop skills in leadership and decision-making. The researchers are interested in identifying the positive effects of Charting on the development of youth. Even though my teenager is not involved in Charting or 4- $\mathrm{H}$, I understand that the researchers need other teenagers to be in the study.

Description of Procedures. The study will be performed in the high school. My teenager will be asked to complete a set of questionnaires at three different times over the next year and a half. The questions will be related to how he/she feels about him/herself, his/her relationships with others, how he/she make decisions, and similar topics. My teenager does not have to answer all of the questions. It will take him/her one to two hours to answer the questions. There will be approximatcly 600 West Virginia adolescents from ages 14 through 19 in the study.

Discomforts. The questions are not supposed to be difficult or disturbing to my adolescent. The only inconvenience is the time that will be given to be in the study.

Benefits. I understand that this study will help 4-H and Extension Services learn more about how Charting helps teenagers.

Contact Persons. For more information about this research, I can contact Dr. Carol Markstrom at (304) 293-3402 ext. 1775 or Dr. Patty Mulkeen at (304) 293-2796 ext. 3438.

For information regarding my child's rights as a research subject, I may contact the Execulive Secretary of the Institutional Review Board at (304) 293-7073.

Confidentiality. T understand that any information obtained as a result of my adolescent's participation in this research will be kept as confidential as legally possible. I understand that these research records, just like hospital records, may be subpoenaed by court order or may be inspected by federal regulatory authorities. In any publications that result from this rescarch, neither my name nor that of my adolescent nor any information from which we might be identified will be mublished. 
-

Voluntary Participation. Participation in this study is voluntary. I understand that I may withdraw my adolescent from this study at any time. Refusal to participate or withdrawal will involve no penalty or loss of benefits for me or my adolescent. I have been given the opportunity to ask questions about the research, and I have received answers concerning areas I did not understand. Upon signing this form, $\mathrm{I}$ will receive a copy.

I willingly consent to my adolescent's participation in this study.

$\begin{array}{lll}\text { Signature of Parent or Guardian } & \text { Date } & \text { Time } \\ \begin{array}{l}\text { Signature of Investigator or } \\ \text { Investigator's Representative }\end{array} & \frac{1 / 67 / 90}{\text { Date }} & \frac{110 \text { tan }}{\text { Time }}\end{array}$




\section{Appendix B}

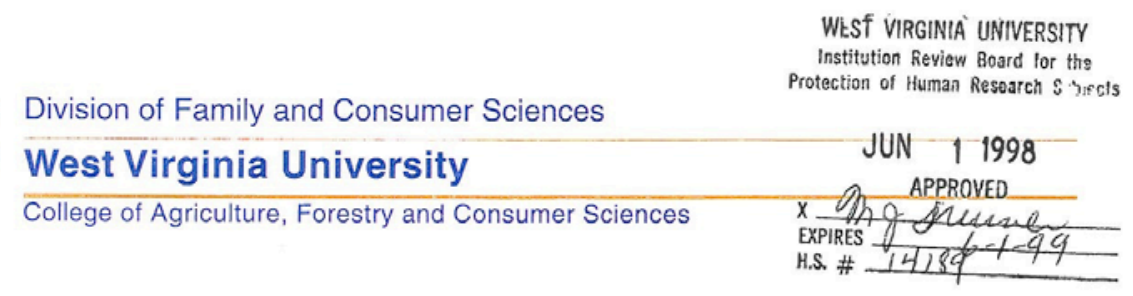

ASSENT FORM - NON-CHARTING PARTICIPANTS

Effects of the 4-H Charting Program on the Development of Youth

Introduction. I, have been asked to be in this research study, which has been explained to me by

Purposes of the Study. I have been told that the purpose of this study is to learn more about the Charting Program offered through 4-H. The researchers are interested in identifying the positive effects of Charting on the development of youth.

Description of Procedures. Even though I am not in Charting, I understand that the researchers need other teenagers to complete a set of questionnaires at three different times over the next year and a half. The questions will be related to how I feel about myself, my relationships with others, how I make decisions, and similar topics. I do not have to answer all of the questions. It will take me one to two hours to answer the questions.

Discomforts. The questions are not supposed to be difficult or disturbing to me. The only inconvenience is the time I will be giving up to be in the study.

Benefits. I understand that this study will help $4-\mathrm{H}$ and Extension people learn more about how Charting helps teenagers.

Confidentiality. I have been promised that anything they learn about me in this study will be kept confidential. Anything that I complete will be given an identification number, instead of my name.

Voluntary Participation. I have been told that I do not have to be in this study. No one will be upset with me if I refuse to do this, or quit after I have started. I have been allowed to ask questions about the research, and all of my questions were answered. I will receive a copy of this form after I sign it.

I willingly agree to be in this study.

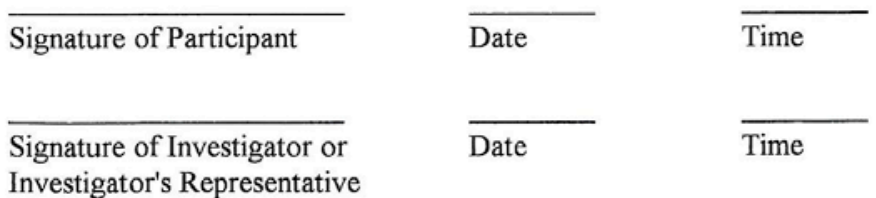




\section{Appendix C}

\section{Volunteer Items}

1. Do you currently do any volunteer work (without pay)?

Yes No

a. How many hours per week? hours

b. Describe your volunteer activity

2. How often do you spend time on the following activities outside of school?

$\begin{array}{llcc}\begin{array}{l}\text { Rarely or } \\ \text { never }\end{array} & \begin{array}{l}\text { Less than } \\ \text { once a week }\end{array} & \begin{array}{c}\text { Once/twice } \\ \text { a week }\end{array} & \begin{array}{c}\text { Every day/almost } \\ \text { every day }\end{array}\end{array}$

\section{Volunteering or performing Community services}




\section{Appendix D}

\section{The Extended Objective Measure of Ego Identity Status (EOMEIS) Ideological Identity Subscale}

Directions: Read each item and indicate to what degree it reflects your own thoughts and feelings. If a statement has more than one part, please indicate your reaction to the statement as a whole. On the line next to each item, write the letter that indicates your answer.

$$
\begin{aligned}
& A=\text { strongly agree } \\
& B=\text { moderately agree } \\
& C=\text { agree } \\
& D=\text { disagree } \\
& E=\text { moderately disagree } \\
& F=\text { strongly disagree }
\end{aligned}
$$

1. I haven't chosen the occupation I really want to get into, and I'm just working at whatever is available until something better comes along.

2. When it comes to religion I just haven't found anything that appeals and I don't really feel the need to look.

3. There's no single "life style" which appeals to me more than another.

4. Politics is something that I can never be too sure about because things change so fast. But I do think it's important to know what I can politically stand for and believe in.

5. I'm still trying to decide how capable I am as a person and what jobs will be right for me.

6. I don't give religion much thought and it doesn't bother me one way or the other.

7. I'm looking for an acceptable perspective for my own "life style" view, but I haven't really found it yet.

8. I haven't really considered politics. It just doesn't excite me much.

9. I might have thought about a lot of different jobs, but there's never really been any question since my parents said what they wanted.

10. A person's faith is unique to each individual. I've considered and reconsidered it myself and know what I can believe.

11. After considerable thought I've developed my own individual viewpoint of what is for me an ideal "life style" and don't believe anyone will be likely to change my perspective. 
12. I guess I'm pretty much like my folks when it comes to politics. I follow what they do in terms of voting and such.

13. I'm really not interested in finding the right job, any job will do. I just seem to flow with what is available.

14. I'm not sure what religion means to me. I'd like to make up my mind but I'm not done looking yet.

15. My own views on a desirable life style were taught to me by my parents and I don't see any need to question what they taught me.

16. There are so many different political parties and ideals. I can't decide which to follow until I figure it all out.

17. It took me a while to figure it out, but now I really know what I want for a career.

18. Religion is confusing to me right now. I keep changing my views on what is right and wrong for me.

19. In finding an acceptable viewpoint to life itself, I find myself engaging in a lot of discussions with others and some self exploration.

20. I've thought my political beliefs through and realize I can agree with some and not other aspects of what my parents believe.

21. My parents decided a long time ago what I should go into for employment and I'm following through with their plans.

22. I've gone through a period of serious questions about faith and can now say I understand what I believe in as an individual.

23. My parents' views on life are good enough for me, I don't need anything else.

24. I'm not sure about my political beliefs, but I'm trying to figure out what I can truly believe in.

25. It took me a long time to decide but now I know for sure what direction to move in for a career.

26. I attend the same church as my family has always attended. I've never really questioned why.

27. I guess I just kind of enjoy life in general, and I don't see myself living by any particular viewpoint to life.

28. I really have never been involved in politics enough to have made a firm stand one way or the other. 
29. I just can't decide what to do for an occupation. There are so many that have possibilities.

30. I've never really questioned my religion. If it's right for my parents it must be right for me.

31. After a lot of self-examination I have established a very definite view on what my own life style will be.

32. My folks have always had their own political and moral beliefs about issues like abortion and mercy killing and I've always gone along accepting what they have. 


\section{Appendix E}

\section{Fidelity Subscale of the Psychosocial Inventory of Ego Strengths}

Directions: Read each item carefully and consider the degree to which it describes you. Write the number signifying your response on the line next to each item.

5

4

3

2

1

Describes Me

Very Well

Does Not

Describe Me

Well

1. I prefer to be free-floating without having to worry about commitments to other people or things.

2. I find that my opinions are frequently influenced by others.

3. When I make a commitment to something, I stick with it.

4. I don’t pretend to be something I'm not.

5. I believe in being true to others and myself.

6. I'm not really sure what I believe in.

7. I have trouble accepting a particular purpose or role in life.

8. I stand up for the people and causes that are important to me. 


\section{Appendix F}

\section{Life Goals Questionnaire}

1. What job would you like to have when you are 25 years old?

2. What do you expect to do after high school? For each question, circle the answer that best describes your plans after high school.

\begin{tabular}{ccc} 
Right away & Later on & Not at all \\
\hline 1 & 2 & 3 \\
1 & 2 & 3 \\
1 & 2 & 3 \\
1 & 2 & 3 \\
1 & 2 & 3 \\
1 & 2 & 3
\end{tabular}

